\title{
Kuznets Curve of Carbon Emissions in China
}

\author{
YANG Xu ${ }^{1,2, a^{*}, \text { FAN DaSha }}{ }^{2, b}$ and LUO Pan ${ }^{2, c}$ \\ ${ }^{1}$ Antai College of Economics \& Management, Shanghai Jiao Tong University, Shanghai 200030, \\ China \\ ${ }^{2}$ College of Geographical Science, Harbin Normal University, Key Laboratory of Remote Sensing \\ Monitoring of Geographic Environment, College of Heilongjiang Province, Harbin 150025, China \\ ayangxu2005gd@163.com, b824619786@qq.com, c1228072128@qq.com
}

Keywords: Economic growth; Carbon emissions; Kuznets curve

Abstract. This paper studied the dynamic relationship between China's carbon emissions and economic growth from 1960 to 2009 . The results indicate that as the economy growed, carbon dioxide emissions has increased steadily since 1960.The use of environmental Kuznets curve model to simulate the relationship of per capita carbon emissions and GDP per capita from 1960 to 2009, the results show China's carbon emissions in line with traditional environmental Kuznets inverted U-shaped curve, China has now broken through the inflection point, the future can be foresee as the economy grows, China's carbon emissions growth will slow down, and gradually reduce, so Chinese energy conservation and emissions reduction can be achieved.

\section{Introduction}

Environmental Kuznets curve (EKC) refers to the economic development of the initial, environmental pollution or environmental damage will increase. With the economic growth, the economy develops to a certain level, the degree of environmental pollution reaches the maximum, then the economy continues to develop, the environment pollution has subsequently declined, the quality of the environment has gradually changed. Many scholars have carried out the research on the environment Kuznets curve hypothesis[1-12]. Many scholars at home and abroad, using different national and regional data, Some special schemes of EKC curve are presented in the same time as the EKC of $U$ curve, There are four main types: inverted $U$ type, the same type, $U$ type and $N$ type[13-16].

Along with the continuous growth of human society and the acceleration of industrialization and urbanization, the ecological environment is deteriorating, in particular, climate warming has been a serious threat to the sustainable development of human beings, to address climate change has become a major challenge facing the world. Since the founding of new China, China's economy has maintained rapid growth, with the concomitant increase in the amount of carbon dioxide emissions continue to rise, the problem of resource and environmental constraints is becoming more and more prominent. Therefore, this paper is based on the hypothesis of environmental Kuznets curve, To study the impact of China's economic development on carbon dioxide emissions, and to investigate whether China's carbon emissions are similar to the development of EKC.

\section{Data sources and research methods}

Data sources. In order to better reflect the dynamic change process, 2000 year as the base year, converted the in 1960 for constant prices (\$) per capita gross domestic product (GDP) said economic growth and PGDP representative. The use of carbon dioxide emissions per capita carbon emissions, said PC. Data sources are mainly the China Statistical Yearbook and the world bank website. In order to eliminate the potential of the different variance problem, but also make the data can be compared in the same dimension, each index has a log processing, the new sequence was named lnPGDP and $\operatorname{lnPC}$.

Research methods. The environmental Kuznets curve (EKC) general model is used to analyze, as shown in formula (1). 


$$
\mathrm{Y}=\mathrm{A}_{1} \mathrm{X}+\mathrm{A}_{2} \mathrm{X}^{2}+\mathrm{A}_{3} \mathrm{X}^{3}+\mathrm{B}+\varepsilon
$$

Among them, $B$ is a constant, $\varepsilon$ is random error, In this model, the parameters of $A_{1}, A_{2}$ and $A_{3}$ show that the per capita GDP of the linear, quadratic and cubic coefficient. For different $A_{i}, i=1,2,3$, the model has different meanings. Specifically, $A_{1}=A_{2}=A_{3}=0$, which shows that the per capita carbon dioxide emissions are not related with the per capita GDP. When $\mathrm{A}_{3} \neq 0$, indicating that the $\mathrm{N}$ type or inverted $\mathrm{N}$ type curve relationship between per capita $\mathrm{CO}_{2}$ emissions and per capita GDP was presented; when $\mathrm{A}_{3}=0$ and $\mathrm{A}_{2}<0$ that per capita carbon dioxide emissions with the per capita GDP is an inverted U-shaped relationship. When $\mathrm{A}_{2}>0$ and $\mathrm{A}_{3}=0$, showed that the per capita carbon dioxide emissions showed a change of $U$ type relationship with per capita GDP. When $A_{2}=0, A_{3}=0$ and $A_{1} \neq 0$, show that the characteristics of per capita carbon dioxide emissions per capita GDP with monotonous change.

\section{Results and Discussion}

China's economic growth and carbon dioxide emissions profile. 2002-2007 years, China has doubled the amount of carbon dioxide emissions, Today, China's carbon dioxide emissions exceed the United States, as the world's largest emitter of greenhouse gases. As shown in Fig. 1, we can see the changes of the Chinese economy and carbon dioxide emissions in 1960-2009, As can be seen from Fig. 1, with economic growth, carbon dioxide emissions are always in steadily increasing, but the growth rate has slowed.

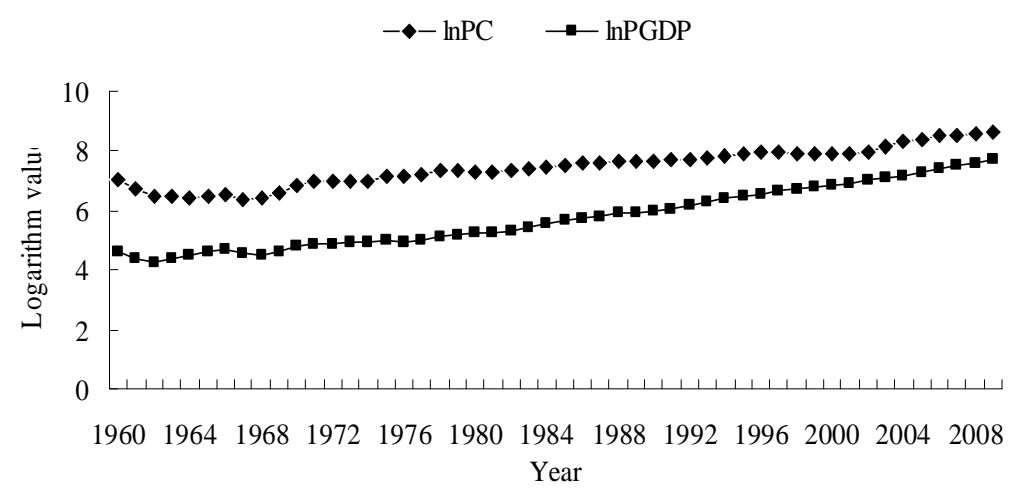

Fig. 1 Time series of $\ln P G D P$ and $\operatorname{lnPC}$

Carbon Emissions Kuznets Curve Model. By using SPSS software, the relationship of $\ln P C$ and lnPGDP are respectively according to the linear equation, quadratic equation and cubic equation, and the results are shown in Table 1.

Table1. fitting model results

\begin{tabular}{lccccc}
\hline Equation & $\mathrm{A}_{1}$ & $\mathrm{~A}_{2}$ & $\mathrm{~A}_{3}$ & $\mathrm{~B}$ & $\mathrm{R}^{2}$ \\
\hline Linear equation (including constant term) & $0.595^{* *}$ & 0 & 0 & $4.037 * *$ & 0.934 \\
Linear equation (non constant term) & $1.276^{* *}$ & 0 & 0 & 0 & 0.991 \\
Quadratic equation (including constant term) & $1.436^{* *}$ & $-0.071^{* *}$ & 0 & 1.621 & 0.943 \\
Quadratic equation (no constant term) & $1.995^{* *}$ & $-0.118^{* *}$ & 0 & 0 & 1.000 \\
Cubic equation (including constant term) & 0 & 0 & 0 & 0 & 0 \\
Cubic equation (no constant term) & $2.362^{* *}$ & $-0.243^{* *}$ & $0.010^{*}$ & 0 & 1.000 \\
\hline
\end{tabular}

As can be seen from Table 1, the quadratic equation (without constant term) is superior to other model fitting in the whole equation. Therefore, we choose the quadratic equation (without constant 
term) in the present study to fit the per capita GDP and per capita carbon dioxide emissions in the relationship, you can get fit equation (2) between per capita GDP and per capita carbon dioxide emissions.

$$
\ln \mathrm{PC}=1.995 \ln \mathrm{PGDP}-0.118 \ln \mathrm{PGPP}^{2}
$$

2)

According to the environmental Kuznets curve of carbon dioxide emissions per capita and per capita GDP in equation (2) constructed between, as shown in Fig. 2.

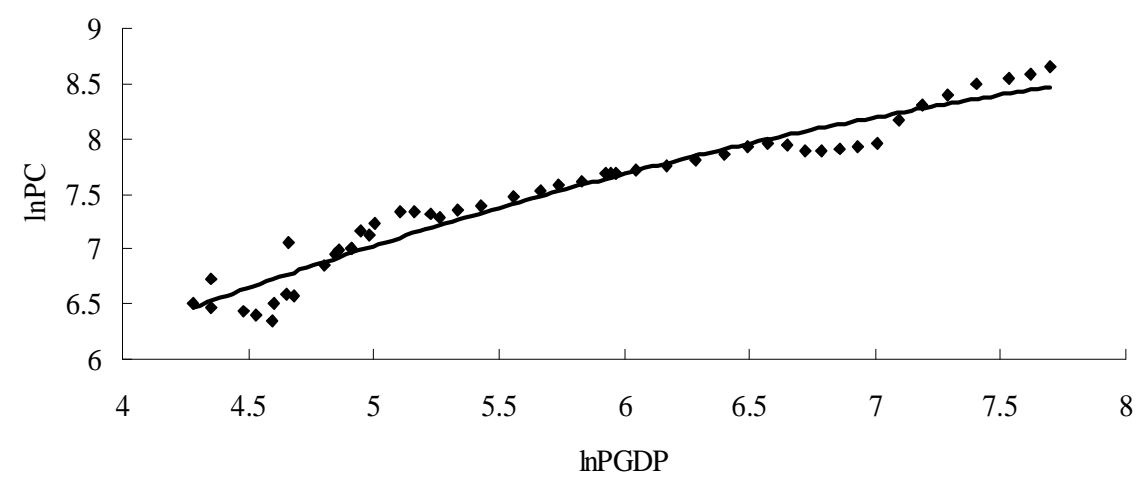

Fig. 2 Relationship between per capita GDP and per capita carbon dioxide emissions

By equation (2), it can be seen, When $\mathrm{A}_{2}<0$ and $\mathrm{A}_{3}=0$, Per capita carbon dioxide emissions and per capita GDP with an inverted U-shaped relationship. It can also be seen from Fig. 2, an inverted U-shaped relationship between China's per capita GDP and per capita carbon emissions which shows kind of carbon emissions in line with the Environmental Kuznets Curve. Meanwhile, according to the equation calculated inflection point position $\mathrm{x}=8.45$, which indicates that China has broken through the inflection point, with further increases in per capita income, carbon emissions will gradually turn from high to low. This shows that advances in technology, government environmental policy and management to strengthen and enhance the environmental awareness of citizens will be constraints on carbon emissions, which played a positive impact, so China energy conservation can be achieved.

\section{Conclusions}

As the economy growed, carbon dioxide emissions has increased steadily since1960- 2009.Chinese carbon emissions in line with traditional environmental Kuznets inverted U-shaped curve, and now China has exceeded inflection point in the future as the economy grows, China's carbon emissions growth will slow down, and gradually reduce, This shows that: China energy saving will be achieved. To speed up the pace of energy conservation, China should actively promote the development and implementation of emission reduction policies, At the same time, in order to achieve to 2020 carbon emissions of per million yuan GDP than that in 2005 carbon emissions by $40 \%-45 \%$, which is the goal of China's government. some measures that need to be implemented, such as enhance energy efficiency, increase the contribution rate of technological progress, and promote industrial restructuring.

\section{Acknowledgment}

This work was financially supported by Heilongjiang Postdoctoral Science-Research Foundation (No. LBH-Q13101) and the Program for Young Academic Backbone of Harbin Normal University (No. 10KXQ-08). 


\section{References}

[1] J. B. Ang. Economic development, pollutant emissions and energy consumption in Malaysia, Journal of Policy Modeling. 30 (2008) 271-278.

[2] M. Fodha, O. Zaghdoud, Economic growth and pollutant emissions in Tunisia: An empirical analysis of the environmental Kuznets curve, Energy Policy. 38(2010)1150-1156.

[3] A. Jalil, S.F. Mahmud, Environment Kuznets curve for $\mathrm{CO} 2$ emissions: A cointegration analysis for China, Energy Policy. 37(2009)5167-5172.

[4]O.Ilhan,A. Usama,Investigating the validity of the environmental Kuznets curve hypothesis in Cambodia, Ecological Indicators,57(2015)324-330.

[5]Q. L. Tan, Z. G. Wen, J. N.Chen, The relationships between industrial pollution intensity and economic growth based on intensity environment Kuznets curve: study on China's pilot cities, International Journal of Sustainable Development and World Ecology .22(2015) 231-241.

[6]S. Muhammad, K. Naceur, U.G. Salah, Environmental Kuznets curve in an open economy: A bounds testing and causality analysis for Tunisia, Renewable \& Sustainable Energy Reviews.34(2014) 325-336.

[7]C. H. Cho, Y. P. Chu, H. Y. Yang, An Environment Kuznets Curve for GHG Emissions: A Panel Cointegration Analysis, Energy Sources Part B-Economics Planning And Policy.9(2014) 120-129.

[8]L. Taedong,V. M. Susan, Comparative studies of urban climate co-benefits in Asian cities: an analysis of relationships between $\mathrm{CO}_{2}$ emissions and environmental indicators, Journal of Cleaner Production.58(2013) 15-24.

[9]S. Muhammad, O. Ilhan, Afza. Talat, A. Amjad, Revisiting the environmental Kuznets curve in a global economy, Orcidrenewable \& Sustainable Energy Reviews,25(2013) 494-502.

[10]B. S. Sinha, D. S. Kishore, The relevance of environmental Kuznets curve (EKC) in a framework of broad-based environmental degradation and modified measure of growth - a pooled data analysis, International Journal of Sustainable Development and World Ecology.20(2013) 309-316.

[11]S. Muhammad, M. Mihai, A. Parvez, Environmental Kuznets curve in Romania and the role of energy consumption, Renewable \& Sustainable Energy Reviews.18(2013) 165-173.

[12]K. Tamas, Looking through the dataquadrate: characterizing the human-environment relationship through economic, hedonic, ecological and demographic measures, Journal of Cleaner Production.35(2012) 1-15.

[13]A.Usama, T. C. Foon, O. Ilhan, Estimating the Environment Kuznets Curve hypothesis: Evidence from Latin America and the Caribbean countries, Renewable \& Sustainable Energy Reviews.2015(50) 918-924.

[14]F. Carlos,F.L. Alfonso, K. Dimitrios, Lessons from quantile panel estimation of the environmental kuznets curve, Econometric Reviews.33(2014) 815-853.

[15]L. Lee, Environmental poverty, a decomposed environmental Kuznets curve, and alternatives: Sustainability lessons from China, Ecological Economics.73(2012)86-92.

[16]Z. Mariana, R. Marina, GDP and environment pressure: The role of energy in Latin America and the Caribbean, ENERGY POLICY.39(2011)7941-7949. 